\title{
NDT of Mechanical Damaged Concrete Specimens by Nonlinear Acoustic Spectroscopy Method
}

\author{
M. Matysik* \& I. Plskova \& M. Korenska \\ Department of Physics, Faculty of Civil Engineering, Brno University of Technology, Veveri 331/95, 60200 \\ Brno, Czech Republic \\ *Corresponding author: matysik.m@fce.vutbr.cz \\ B. Kucharczykova \\ Institute of Building Testing, Faculty of Civil Engineering, Brno University of Technology, Veveri 331/95, \\ 60200 Brno, Czech Republic
}

\begin{abstract}
Current research and development of non-linear ultrasonic spectroscopy methods shows these methods to be very promising for material testing and defectoscopy in the near future. Our experiments focused on the testing of lightweight concrete specimens using the single-frequency excitation method. We studied the concrete specimens' structure after having been stressed by a mechanical force. Measurements were realized before and after mechanical loading.
\end{abstract}

KEY WORDS: non-linear acoustic spectroscopy, light concrete, freeze-thaw cycles

\section{INTRODUCTION}

According to the relevant standards, there are three kinds of concrete: lightweight, plain and heavyweight concrete. By definition, the volume mass of lightweight concrete is less than $2000 \mathrm{~kg} / \mathrm{m}^{3}$. Depending on the intended application, the lightweight concrete group consists of three subgroups: thermal insulating lightweight concretes, their intended application falling into the thermal insulation field, furthermore, structural insulating lightweight concretes, their function being both supporting and insulating, and, last but not least, structural lightweight concretes, whose main function is their bearing capacity and the main requirement is strength combined with low volume mass. (Kucharczykova \& Kersner, 2008; Korenska et al. 2005, Plskova et al. 2009)

On the basis of non-linear effect studies, new NDT methods have been designed (Van den Abeele et al. 2000, Zaitsev et al. 2006). These methods are based on the elastic wave non-linear spectroscopy. Existing linear acoustic methods focus on the energy of waves reflected at structural defects, analyzing the reflected wave energy, wave velocity or amplitude variations. However, none of these "linear" wave characteristics is as sensitive to small cracks as the specimen non-linear response (Nagy, 1998; Van den Abeele et al. 2001; Van den Abeele et al. 2009). In this way, non-linear methods thus open new horizons in nondestructive acoustic testing, providing undreamed-of sensitivities, application speeds and easy interpretation. One of the fields in which a wide application range of non-linear acoustic spectroscopy methods can be expected is civil engineering, for example, for fatigue damage assessment (Nagy, 1998), micro-damage diagnostics (Van den Abeele et al. 2001; Chen 
2008), or monitoring of the early hydration process in concrete (Van den Abeele et al. 2009). It is predicted that these advanced techniques can contribute a great deal to the improvement and refinement of the NDT methods in the building industry practice.

\section{EXPERIMENT}

Lightweight concrete specimens have been studied in our experiments. A fresh concrete mix consisted of the following: 0-4 $\mathrm{mm}$ natural gravel and sand, Liapor CZ4-8/600 lightweight porous aggregates, CEM I - 42,5 R cement, fly-ash, plasticiser and water. Water and lightweight porous aggregates were gauged by volume; all other components were gauged by mass.

Joists of dimensions $100 \times 100 \times 400 \mathrm{~mm}$ were made of the lightweight concrete. To produce the test specimens, moulds were filled progressively in two layers, each of them being vibrated for a period of 30 seconds. After 24 hours, the joists were removed from the moulds to be placed into a tank with PE foil covered wooden slat grids and a constant water level at the bottom. The tank was kept in the laboratory at a temperature of $20 \pm 1{ }^{\circ} \mathrm{C}$ and relative humidity $\mathrm{RH} 50 \pm 5 \%$. The joist volume mass amounted to $1700 \mathrm{~kg} / \mathrm{m}^{3}$ after 28 days.

Hardened concrete specimens were prepared for pressing machine tests. A notch $8 \mathrm{~mm}$ wide and $33 \mathrm{~mm}$ deep (one third of the joist height) was cut at the joist centre - see Fig. 1 . Subsequently, first specimen measurements were carried out prior to the pressing machine tests.

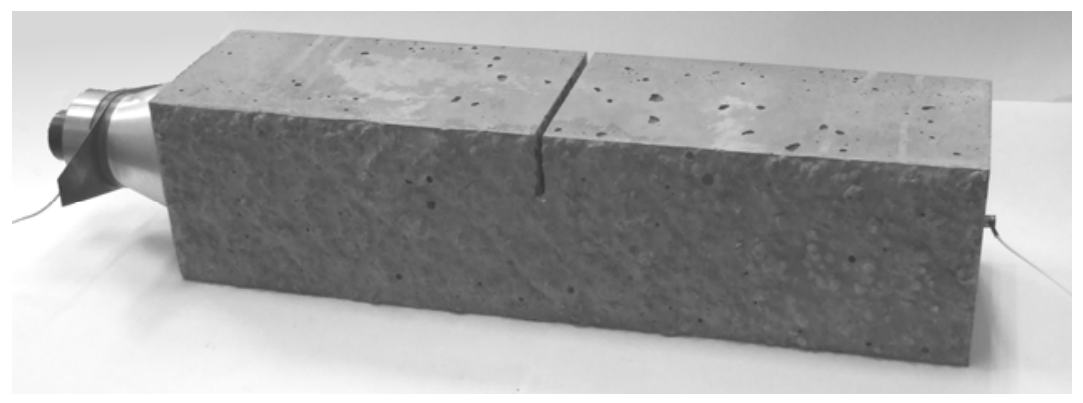

Figure 1: Joist fitted with exciter and sensor.

In the pressing machine, the joist was placed on 2 supports. Force $F$ was applied to the joist at its centre (see Fig 2) - which is the case of three-point bending of a notched joist. The force F was increased gradually until a crack occurred (it arose at the notch root, Fig. 3). The force grew very slowly in order to prevent joist breakage, only the formation of a crack being desirable. Subsequently, the second specimen measurement stage was carried out.

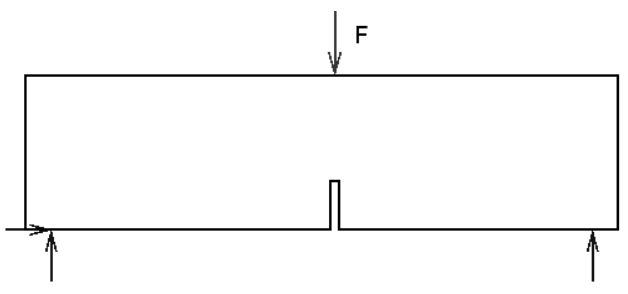

Figure 2: Three-point bending of a notched joist.

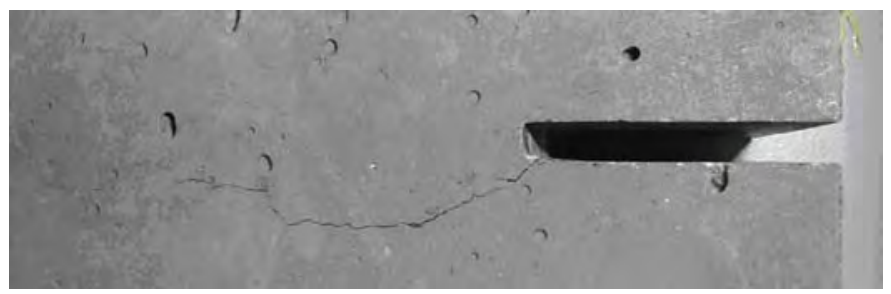

Figure 3: Post-stress LC_09_01 specimen - detailed view of the crack. 


\section{MEASURING METHOD}

We classify non-linear acoustic spectroscopy methods into resonant and non-resonant (Korenska \& Manychova, 2008; Hajek \& Sikula, 2008). Non-resonance methods are used to study suppressed resonance specimens. These methods analyze the effect of nonlinearities on acoustic signals propagating through them. These methods can again be split into two groups (Korenska \& Manychova, 2008): measurements using a single harmonic ultrasonic signal (single exciting frequency) and measurements using multiple harmonic ultrasonic signals - mostly two exciting frequencies. There is also the possibility to combine one ultrasonic and one electrical signal with different frequencies (Sikula et al. 2008).

We pay particular attention to the single harmonic ultrasonic signal measurement method which was used in the experimental part.

\section{MEASURING APPARATUS}

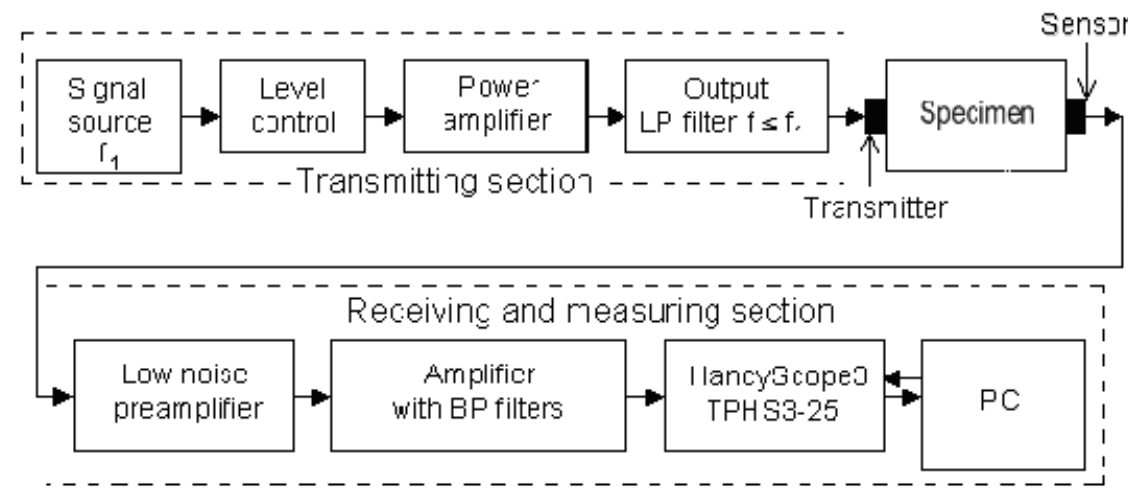

Figure 4: Block diagram of the measuring apparatus.

The transmitting section of measuring apparatus consists of four functional blocks: a controlled-output-level harmonic signal generator, a low-distortion $100 \mathrm{~W}$ power amplifier, an output low-pass filter to suppress higher harmonic components and ensure the high purity of the exciting harmonic signal and a piezoceramic transmitter (actuator) to ensure the ultrasonic excitation.

The receiving section consists of a piezoceramics sensor, a low noise preamplifier with classical or differential input connector, an amplifier with band - pass filters and a spectral analyzer. In our case the spectral analyzer was the oscilloscope HandyScope3 TPHS3-25 controlled by computer.

For the recorded data to be interpreted properly, each of the measuring instruments must meet the following criteria:

- High linearity of all instruments (generators, amplifiers, sensor, transmitter,...).

- High resolution in the frequency domain.

- High dynamic range (90 to $130 \mathrm{~dB}$ ).

- Highly efficient filtration of detected signals (fundamental frequency suppression).

- Frequency range $10 \mathrm{kHz}$ to $10 \mathrm{MHz}$.

- Optimized sensor and transmitter location.

A program package to control the measuring process and the data processing and evaluation makes an indispensable tool. 


\section{MEASUREMENT RESULTS}

The measurement results are presented in figures 5 and 6. They show the frequency spectra from both measurement stages, prior to and after the pressing machine test.

In Fig. 5, a change in the specimen response is seen to correlate with the specimen structure change. The pre-stress curve features an amplitude fall with growing harmonic frequency order, no non-linearity being apparent. The post-stress frequency spectrum, corresponding to the specimen structural integrity being impaired, shows - in consequence of higher damping - lower amplitudes by about $20 \mathrm{~dB}$. The fourth and the fifth harmonic components vanished almost entirely. Several other frequency components are emphasized in the spectrum.

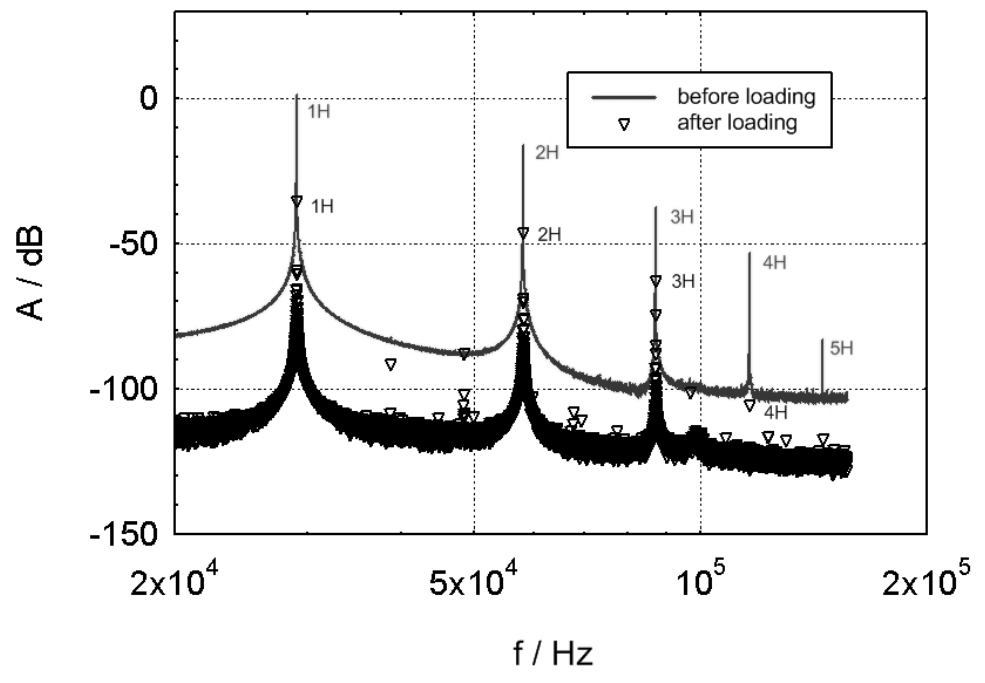

Figure 5: Frequency spectrum - specimen LC_09_01.

In the frequency spectrum of post-stress LC_09_02 specimen measurement, Fig. 6, a change in the second harmonic frequency is seen. Its amplitude is comparable with that of the first (exciting) harmonic. The fourth and the fifth harmonic frequency components almost vanished again. Several components of various frequencies are observed in the spectrum. Other specimens provided similar results.

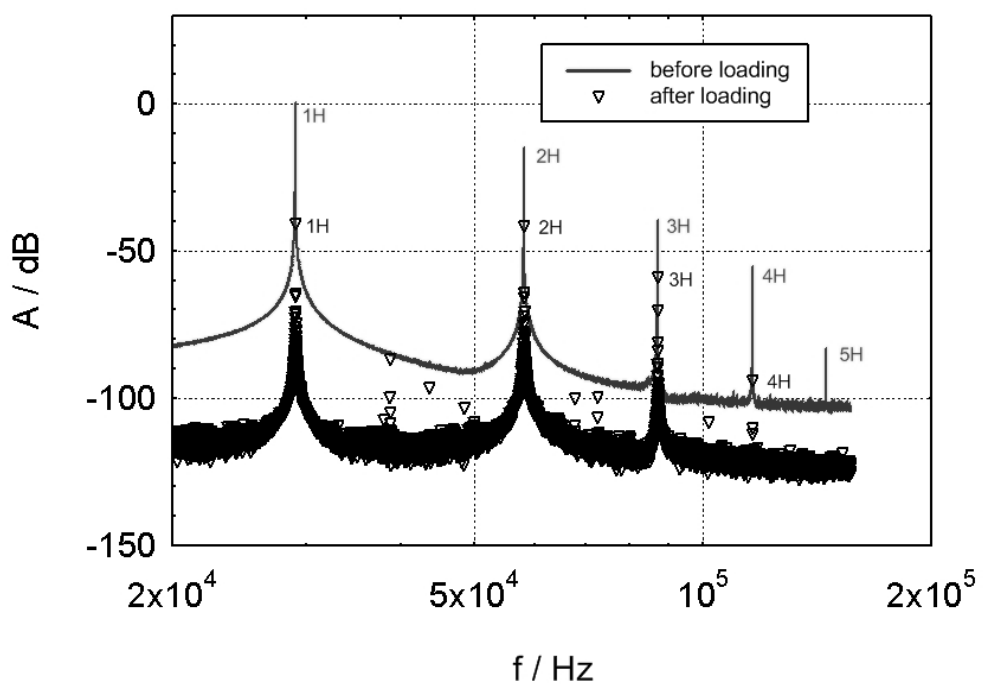

Figure 6: Frequency spectrum - specimen LC_09_02. 


\section{CONCLUSION}

The following pieces of knowledge follow from the result analysis:

- High inhomogeneity induced non-linear effects are substantially weaker than those due to "normal" defects.

- The notch forced into the joist does not make a source of non-linear phenomena.

- Material structure defects give rise to non-linear effects during the signal transmission.

\section{ACKNOWLEDGEMENT}

This research is supported by Czech Science Foundation - project GP103/09/P252 and by Ministry of Education, Youth and Sports, project No. 1M06005, within the activities of the CIVAK research centre.

\section{REFERENCES}

Kucharzcyková, B., Keršner, Z. 2008. Fracture properties of lightweight concrete: Influence of specimen age. In Proceedings of the International Conference LC2008, Brno, Akademické nakladatelství CERM, 2008, p. 174 - 179.

Van Den Abeele, K.E.-., Johnson, P.A. and Sutin, A., 2000. Nonlinear Elastic Wave Spectroscopy (NEWS) techniques to discern material damage, Part I: nonlinear wave modulation spectroscopy (NWMS). Research in Nondestructive Evaluation, 12(1), pp. 1730. ISSN: 09349847

Van Den Abeele, K.E.-., Carmeliet, J., Ten Cate, J.A. and Johnson, P.A., 2000. Nonlinear elastic wave spectroscopy (NEWS) techniques to discern material damage, Part II: singlemode nonlinear resonance acoustic spectroscopy. Research in Nondestructive Evaluation, 12(1), pp. 31-42. ISSN: 09349847

Zaitsev, V., Nazarov, V., Gusev, V. and Castagnede, B., 2006. Novel nonlinear-modulation acoustic technique for crack detection. NDT and E International, 39(3), pp. 184-194. ISSN: 09638695

Nagy, P.B., 1998. Fatigue damage assessment by nonlinear ultrasonic materials characterization. Ultrasonics, 36(1-5), pp. 375-381. ISSN: 0041624X

Van Den Abeele, K.E.-., Sutin, A., Carmeliet, J. and Johnson, P.A., 2001. Micro-damage diagnostics using nonlinear elastic wave spectroscopy (NEWS). NDT and E International, 34(4), pp. 239-248. ISSN: 09638695

Chen, X.J., Kim, J.-., Kurtis, K.E., Qu, J., Shen, C.W. and Jacobs, L.J., 2008. Characterization of progressive microcracking in Portland cement mortar using nonlinear ultrasonics. NDT and E International, 41(2), pp. 112-118. ISSN: 09638695

Van Den Abeele, K., Desadeleer, W., De Schutter, G. and Wevers, M., Active and passive monitoring of the early hydration process in concrete using linear and nonlinear acoustics. Cement and Concrete Research, . in print ISSN: 00088846 
Stauffer, J.D., Woodward, C.B. and White, K.R., 2005. Nonlinear ultrasonic testing with resonant and pulse velocity parameters for early damage in concrete. ACI Materials Journal, 102(2), pp. 118-121. ISSN: 0889325X

Korenska, M. and Manychova, M., 2008. Nonlinear ultrasonic spectroscopy used to detection of ceramic structure damage. Nonlinear Acoustics Fundamentals and Applications, Aip Conference Proceedings. 18th International Symposium on Nonlinear Acoustics, Stockholm, Sweden, 2008, pp. 541-544. ISSN: 0094243X, ISBN: 9780735405448

Sikula, J., Sedlakova, V., Navarova, H., Tofel, P., Majzner, J. and Hajek, K., 2008. NDT of conducting solids by electro-ultrasonic spectroscopy, 2008, Nonlinear Acoustics Fundamentals and Applications, Aip Conference Proceedings. 18th International Symposium on Nonlinear Acoustics, Stockholm, Sweden, 2008, pp. 319-322. ISSN: 0094243X, ISBN: 9780735405448

Hajek, K. and Sikula, J., 2008. A resonance frequency shift in spectral analysis of the impact echo. Nonlinear Acoustics Fundamentals and Applications, Aip Conference Proceedings. 18th International Symposium on Nonlinear Acoustics, Stockholm, Sweden, 2008, pp. 525-528. ISSN: 0094243X, ISBN: 9780735405448

Korenska, M., Pazdera, L., Pospisil, K., Stryk, J. and Vyroubal, P., 2005. Detection of the reinforcement corrosion in prestressed concrete girders. Application of Contemporary NonDestructive Testing in Engineering. ${ }^{\text {th }}$ International Conference of the Slovenian-Societyfor-Non-Destructive-Testing on the Application of Contemporary Non-Destructive Testing in Engineering. Portoroz, Slovenia, 2005. pp. 317-322. ISBN: 9619061055

Plskova, I.; Kucharczykova, B.; Matysik, M.; Chobola, Z. 2009.Non-Destructive Testing of Lightweight Concrete Specimen by Impact-Echo Method. The e-Journal of Nondestructive Testing, 2009, 14(3), p. 1 - 6.

Mazal, P.; Pazdera, L., 2005. Advanced Acoustic Emission Signal treatment in the Area of Mechanical Loading. In The 8th Int.Conf. of the Slovenian Soc.for NDT "Application of Contemporary NDT in Engineering". Portorož, SSNDT Slovenia. 2005. pp. 283 - 292. ISBN 961-90610-5-5.

Korenska, M.; Pazdera, L.; Pospisil, K., 2006. Detection of the reinforcement corrosion in pre-stressed concrete girders. International Journal of Microstructure and Materials Properties . 2006. 2006(1)(3/4). p. 374 - 382. ISSN 1741-8410. 